\title{
Factor influences in the food industry of the example of dairy processing enterprises in Bulgaria
}

\author{
Oleg Milev ${ }^{1^{*}}$ \\ ${ }^{1}$ Trakia University, Faculty of Economics, Department of Economics, Student campus, 6000 Stara \\ Zagora, Bulgaria
}

\begin{abstract}
The purpose of this article is to examine the factors that affect the sales revenues of companies in the food industry with a subject of business activity of processing milk and dairy products. Based on available statistical information and applied theoretical statements, a method of analysis was chosen related to the change in sales revenues from the volume, price and range of produced and sold types of dairy products. By studying the relationships and dependencies of factor influences, it is possible to optimize production capacity and to do more effective strategic planning. The obtained result of the research is the basis for deriving guidelines and recommendations in order to increase the financial result of the dairy processing enterprises in Bulgaria.
\end{abstract}

\section{Introduction}

The secondary sector (manufacturing) is the most important sector in Bulgaria and has a significant contribution to the Gross Domestic Product (GDP). The food industry is part of the secondary sector and accounts for about $20 \%$ of all industrial production in Bulgariaamounting to $\$ 7.06$ Billion. Around 6,300 companies are registered in the sector, with almost 100,000 employed.

The food industry produces food and products that satisfy people's daily needs and ensure the normal functioning of the human body. This determines the industry's social significance. The leading sub-sectors within the food industry are the production and processing of bakery, dairy and meat products, as well as processing of fruits and vegetables, sweets, etc. [1]

Milk production (cow, buffalo, sheep and goat) is of strategic importance for Bulgaria. Milk is a vital product present in the daily diet, but in addition to its social and health effects, the dairy sector contributes to the provision of permanent jobs in rural areas, as well as to the protection of the environment. The crisis in the dairy sector across Europe has led to lower purchase prices and further challenged the survival of dairy farms. The main efforts in the sector are focused on investments at all stages of the milk and dairy products chain, starting with investments in higher quality genetic material, modernization of agricultural holdings, milk collection facilities and dairy processing plants, as well as trade encouragement,

* Corresponding author: oleg.milev@trakia-uni.bg 
especially export. Of all products in the dairy sector, Bulgaria has a strong export potential for yogurt, cheese and yellow cheese, obtained from various types of milk produced in the country. [2]

The largest in volume from the dairy products produced are yogurt, packaged milk, white brined cheese and yellow cheese.

In addition to traditional agriculture, organic farming has increased significantly in Bulgaria. The reasons for this are both the increased local purchasing power and the growing consumer demand, as well as the subsidies from the EU. However, the sector still has a low processing capacity and therefore $80 \%$ of the organic products are for export. [1]

Revenue from sales of products is a major factor influencing the profits. Enterprises, regardless of what they are producing, form their income primarily from the sale of their products or services. [3] The companies with main activity related to the production and processing of milk and dairy products form their financial profits primarily from the revenues from the actual production, valued at the respective price.

The provision of information from the analysis of the revenues from sales can be performed based on data from the income statements and balance sheets of the company. In this particular case, this revenue is from the sale of milk and dairy products and is reported as revenue from sales of services and revenue from sales of goods.

The methodology of the analysis is related to the reporting of the value of sales during a given reporting period and may deviate from the planned sales or from the sales of the previous period- either increase or decrease. This deviation is due to three main factors: the quantity of the real production, the assortment structure, taking into consideration the main types of dairy products, and the price for those products. [4]

The dynamics of the revenues from the sale of the respective dairy product structured by type, price range and years makes it possible to make a comparative analysis and forecast the financial result. For reporting and planning of sales revenues a combined spatial-temporal structure is used in combination with the individual ones structural elements. The planning of the financial result depends not only on the different types of activities but from the demand, employment and economic trends in the region. [5]

According to the classification of economic activities (NACE.BG-2008), section 10 "Food production" is part of sector C "Processing industry".

The empirical study covers over 200 companies registered in the Commercial register with activity related to subsector 10.5 - "Milk and dairy production" in Bulgaria in the period 2015 - 2020. [6]

\section{Methodology for analysis of revenues from sales of milk and dairy products}

Revenues from sales of products are a major generator of profit and profitability in the sector. In some areas, small fluctuations in sales volume have a strong effect on the amount of profit.

There are many factors that affect the volume of sales and revenues from the production of milk and dairy products. The direct factors on which the amount of sales revenue (Q) depends are the quantity of sales, the assortment structure and the sales price. [7]

In the production of milk and dairy products, these factors are:

- $\quad$ The quantity of dairy products produced and sold on the market (q);

- $\quad$ The range in relation to the main types of dairy products $(d)$;

- $\quad$ Average wholesale price for the product (p).

$$
\mathrm{Q}=\sum_{i=1}^{n} q_{i} \cdot d_{i} \cdot p_{i}
$$


In the present article, the number of cases studied (n) is related to the main dairy products, which take up about $95 \%$ of the total production in the sector and are differentiated into 4 main groups:

- Milk;

- Yoghurt;

- White brined cheese;

- Cheese.

The influence of the three factors on the change in sales revenue can be established using two approaches:

1. Index multiplicative factor analysis in the study of the relative change in income;

2. Method of successive substitution in the study of the absolute change in sales revenue. In the first approach we can calculate the following 3 indices:

- $\quad$ Real sales volume growth index $(Y q)$

$$
Y_{q}=\frac{\sum q_{1} \cdot d_{0} \cdot p_{0}}{\sum q_{0} \cdot d_{0} \cdot p_{0}}
$$

- $\quad$ Index of changes in the assortment structure $(Y d)$

$$
Y_{d}=\frac{\sum q_{1} \cdot d_{1} \cdot p_{0}}{\sum q_{1} \cdot d_{0} \cdot p_{0}}
$$

- $\quad$ Price index $(Y p)$

$$
Y_{p}=\frac{\sum q_{1} \cdot d_{1} \cdot p_{1}}{\sum q_{1} \cdot d_{1} \cdot p_{0}}
$$

The second approach to analysis, which is based on successive substitution, examines the influence of the same factors on the absolute change in sales revenue of the tourist product, marked with (Inf) and defined as the difference between two consecutive revenue values and is as follows:

- $\quad$ Impact of the actual increase in sales volume (inf q)

$$
\inf _{q}=\sum q_{1} \cdot d_{0} \cdot p_{0}-\sum q_{0} \cdot d_{0} \cdot p_{0}
$$

- $\quad$ Impact of the assortment structure (inf d)

$$
\text { inf } f_{d}=\sum q_{1} \cdot d_{1} \cdot p_{0}-\sum q_{1} \cdot d_{0} \cdot p_{0}
$$

- $\quad$ Impact of prices (inf p)

$$
\inf _{p}=\sum q_{1} \cdot d_{1} \cdot p_{1}-\sum q_{1} \cdot d_{1} \cdot p_{0}
$$

\section{Analysis of revenues from sales of milk and dairy products}

From the data presented in Table 1 it is evident that the total amount of milk produced in Bulgaria for the study period decreases with each year, reaching 900350 liters in 2020, which compared to 2015 is a decrease of about $19.5 \%$. This can be explained by the fact that a large number of farmers are switching their activities from dairy to beef cattle breeding, as they find it difficult to bring their farms in line with European requirements for the production of quality dairy raw materials.

The situation with the data from the total amount of processed milk is different, where at the end of the period compared to 2015 there is an increase of about $36 \%$. This is due to the reduced quantities of production intended for direct sales, own consumption and other use of milk on farms, which decreased from $50 \%$ at the beginning to $20 \%$ at the end of the period. 
It is logical that with the increase in the quantities of processed products there is also an increase in the number of enterprises related to the processing of milk and dairy products, from 215 in 2015 to 240 in 2020 .

The largest share is occupied by the amount of processed cow's milk, which amounts to about $94 \%$ of the total amount of processed milk in Bulgaria for the period under review.

Table 1. Indicators characterizing the dairy industry in Bulgaria

\begin{tabular}{|c|c|c|c|c|c|c|}
\hline Indicators & $\mathbf{2 0 1 5}$ & $\mathbf{2 0 1 6}$ & $\mathbf{2 0 1 7}$ & $\mathbf{2 0 1 8}$ & $\mathbf{2 0 1 9}$ & $\mathbf{2 0 2 0}$ \\
\hline $\begin{array}{c}\text { Total milk produced } \\
\text { (in thousand liters) }\end{array}$ & 1118704 & 1114846 & 1059376 & 995023 & 911854 & 900350 \\
\hline $\begin{array}{c}\text { Total milk processed } \\
\text { (in thousand liters) }\end{array}$ & 523189 & 543844 & 600914 & 661355 & 670085 & 713658 \\
\hline $\begin{array}{c}\text { including cow's milk } \\
\text { (in thousand liters) }\end{array}$ & 493236 & 508772 & 561932 & 624178 & 632538 & 675023 \\
\hline $\begin{array}{c}\text { Number of milk } \\
\text { processing companies }\end{array}$ & 215 & 213 & 220 & 237 & 238 & 240 \\
\hline
\end{tabular}

In the studied period 2015-2020, under the complex influence of the three factors, the amount of sales, assortment structure and price of dairy products, there is a generally positive trend. (Table 2)

Table 2. Results of index factor influences in the production of milk and dairy products

\begin{tabular}{|c|c|c|c|}
\hline Periods & $\begin{array}{c}\text { Real sales volume } \\
\text { growth index (Yq) }\end{array}$ & $\begin{array}{c}\text { Index of changes in the } \\
\text { assortment structure (Yd) }\end{array}$ & $\begin{array}{c}\text { Price index } \\
\text { (Yp) }\end{array}$ \\
\hline $\mathbf{2 0 1 6} / \mathbf{2 0 1 5}$ & 0,9987 & 1,0264 & 1,0143 \\
\hline $\mathbf{2 0 1 7} / \mathbf{2 0 1 6}$ & 1,0925 & 1,0125 & 1,1627 \\
\hline $\mathbf{2 0 1 8} / \mathbf{2 0 1 7}$ & 0,9613 & 1,0314 & 1,0494 \\
\hline $\mathbf{2 0 1 9} / \mathbf{2 0 1 8}$ & 1,0882 & 0,9835 & 1,0189 \\
\hline $\mathbf{2 0 2 0} / \mathbf{2 0 1 9}$ & 1,0765 & 0,9833 & 1,0479 \\
\hline
\end{tabular}

Proof of this are the values of all three indicators, which for most of the period under consideration are greater than 1 , leading to a positive financial result of sales revenues.

The volume growth index in the initial periods has fluctuating values that are close to the positive values. The exact opposite is the index of the change in the assortment structure, which has negative values for the last 2 years. It is logical for these two indices to have inconsistencies in the results, as this is related to market consumption and taste preferences of consumers. In the price index the results are positive for the whole period and cover the negative results of the other indices, which means that the companies have a good and balanced price policy.

The highest values of sales revenues from milk and dairy products were achieved in the period 2017/2016, where it is evident that the indices of the three factors are greater than 1 , 
which leads to the highest absolute value of sales revenues amounting to BGN 235,977. The largest contribution to this is the price index, which has the highest value of 1.1627 , and only the influence of this factor leads to an increase in sales revenue by BGN 148,461.

Table 3. Results of value factor influences in the production of milk and dairy products

\begin{tabular}{|c|c|c|c|}
\hline Periods & $\begin{array}{c}\text { Impact of the actual } \\
\text { increase in sales volume } \\
\text { (inf q) }\end{array}$ & $\begin{array}{c}\text { Impact of the } \\
\text { assortment structure } \\
\text { (inf d) }\end{array}$ & $\begin{array}{c}\text { Impact of } \\
\text { prices } \\
\text { (inf p) }\end{array}$ \\
\hline $\mathbf{2 0 1 6} / \mathbf{2 0 1 5}$ & -1057 & 20887 & 11591 \\
\hline $\mathbf{2 0 1 7} / \mathbf{2 0 1 6}$ & 76281 & 11235 & 148461 \\
\hline $\mathbf{2 0 1 8} / \mathbf{2 0 1 7}$ & -41039 & 32045 & 51991 \\
\hline $\mathbf{2 0 1 9} / \mathbf{2 0 1 8}$ & 97408 & -19811 & 22281 \\
\hline $\mathbf{2 0 2 0} / \mathbf{2 0 1 9}$ & 92117 & -21628 & 61022 \\
\hline
\end{tabular}

In the period 2018/2017, some of the indicators have low values and have a negative impact on sales revenues. An example of this is the volume growth index, which has the lowest values during the studied period $(\mathrm{Yq}=0.9613)$, calculated in value terms amounts to BGN -41039. However, the above period has a positive trend, as the negative result of the sales volume factor is covered by the positive influence of the other two factors - assortment structure and sales prices of dairy products.

Excluding the period 2017/2016, where all three indicators have positive values, in the other periods they report partial negative results in some of the factors. Despite these fluctuations, there is a positive trend as an absolute value in sales revenues under the complex influence of the three factors during the study period 2015-2020. Although some of the index indicators over the years are below one, which leads to negative results in value terms, this is covered by the positive impact of the other two factors that cover these losses. In this way, a positive result is achieved in sales revenues from the production and processing of milk and dairy products.

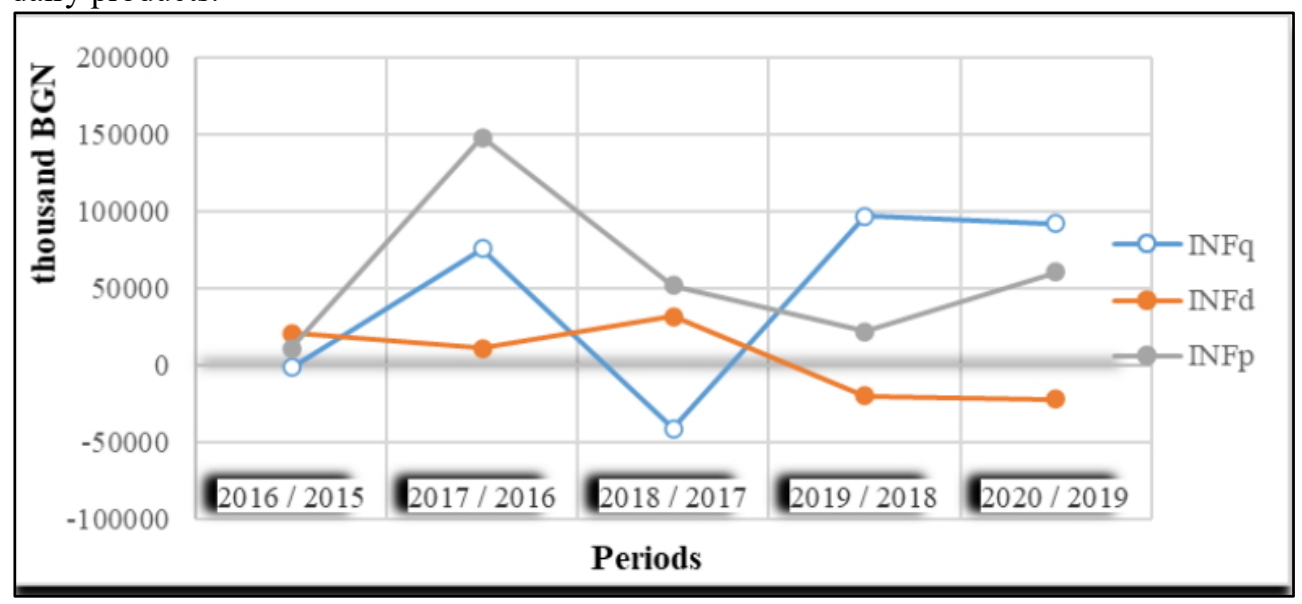

Fig. 1. Graphical representation of value factor influences 
For greater visibility, the graphical expression of the absolute change in sales revenue in the processing of milk and dairy products is illustrated, which describes the trend due to the action of the three-factor model. From it can be evidently seen the positive and negative values during the certain periods of time.

\section{Conclusion}

The COVID-19 pandemic crisis has affected all sectors of the economy. Despite the stable growth and the environment, the food industry has also suffered, though not as much as other sectors. The food industry has proven to be one of the most resilient in this difficult environment. The shock of the pandemic has made it necessary to accelerate corrective action in the sector - such as digitalization, more informed consumer choices and preferences for local products.

The results of the applied methodology for analysis under the influence of direct factors such as quantity of sales, assortment structure and wholesale price of the main types of products on the change in sales revenues in the production and processing of milk and dairy products can be concluded:

- During the studied period 2015-2020 there is a positive trend in the studied indicators;

- The good financial result presented by the growth of sales revenues is largely due to the increase in wholesale prices rather than the increased sales volume and assortment structure of milk and dairy products;

- Fluctuations and negative results in individual factors during certain periods are covered by the positive complex influence of other factors.

The main factors that can contribute to increasing the efficiency of the subsector "Milk and dairy products" as part of the food industry in Bulgaria are the consolidation of farms, improving breeding and selection activities, rational animal nutrition, increasing the average milk yield and the acquisition of specialized qualification on the part of farmers, which would lead to optimization of production costs.

\section{References}

1. Institute for Agrostrategies and Innovation, Food Foresight: Impact of COVID-19 on the food sector in Central and Eastern Europe, Country Report: Bulgaria, (EIT 2020)

2. Minustry of Agriculture, Food and Forestry, Sastoianie i tendenzii na proizvodstvoto na mliako i mlechni produkti v Bulgaria, (Sofia 2017)

3. K. Chukov, Analysis of net sales of production, Institute of Certifiedpublic Accountants (ICPA), Analysis, 4, XXIII, Sofia (2019)

4. M. Timchev, Finansovo-stopanski analiz, (izd. Trakia-M, Sofia 1999)

5. K. Chukov, Finansovo-stopanski analiz na predpriatieto, (UI Stopanstvo, Sofia, 2011)

6. Classification of economic activities 2008 (NACE.BG-2008), Bulgaria

7. L. Todorov, Rentabilnost i biznes risk, (izd. Trakia-M, Sofia 2003) 